Virginia Commonwealth University

vCU Scholars Compass

Social Work Publications

School of Social Work

2013

\title{
Ethnicity and Gender Comparisons of Health Consequences in Adults with Alcohol Dependence
}

Karen G. Chartier

Virginia Commonwealth University, kgchartier@vcu.edu

Michie N. Hesselbrock

University of Connecticut School of Medicine and Dentistry

Victor M. Hesselbrock

University of Connecticut School of Medicine and Dentistry

Follow this and additional works at: http://scholarscompass.vcu.edu/socialwork_pubs

Part of the Race and Ethnicity Commons, Social Work Commons, and the Substance Abuse and Addiction Commons

Copyright $(2013$ Informa Healthcare USA, Inc. This is the author's version of a work that was accepted for publication in Subst Use Misuse. 2013 February; 48(3): 200-210. The final publication is available at http://dx.doi.org/10.3109/ 10826084.2013.747743.

\section{Downloaded from}

http://scholarscompass.vcu.edu/socialwork_pubs/4

This Article is brought to you for free and open access by the School of Social Work at VCU Scholars Compass. It has been accepted for inclusion in Social Work Publications by an authorized administrator of VCU Scholars Compass. For more information, please contact libcompass@vcu.edu. 


\title{
Ethnicity and Gender Comparisons of Health Consequences in Adults with Alcohol Dependence
}

\author{
Karen G. Chartier, Ph.D. ${ }^{\star}$, Michie N. Hesselbrock, Ph.D., and Victor M. Hesselbrock, Ph.D. \\ University of Connecticut School of Medicine, 263 Farmington Avenue, Farmington, Connecticut, \\ 06030
}

\begin{abstract}
The moderating effects of ethnicity and gender on factors associated with physical health consequences in adults with alcohol dependence was examined using data from the 2001-2002 U.S. National Epidemiologic Survey on Alcohol and Related Conditions (NESARC). Black and White respondents with a lifetime diagnosis of DSM-IV alcohol dependence were selected for the study $(n=3,852)$. A multiple-group structural equation model tested ethnicity, gender, and intervening variables as predictors of physical health status in alcohol dependent men and women. Study findings offer implications for clinical practice with alcohol dependent individuals by identifying likely target groups and problems for intervention.
\end{abstract}

\section{Keywords}

alcohol; alcohol dependence; physical health; health consequences; gender; ethnicity; race

\section{Introduction}

The adverse physical health effects of alcohol misuse and dependence are well established (NIAAA, 2000). Room, Babor and Rehm (2005), in reviewing the role of alcohol in health and illness, attributed four percent of the global burden of disease to alcohol. In a residential detoxification, chronic medical conditions were documented in $47 \%$ of individuals with alcohol use disorders (De Alba et al., 2004). Health consequences likely to affect persons with alcohol dependence are both acute and chronic. Chronic disease conditions attributed to alcohol include hepatitis, cirrhosis, cardiomyopathy, and gastritis, while acute health consequences may involve accidental injury and/or death (Rehm et al., 2003).

Blacks and women are often identified as vulnerable subgroups to the negative health effects of chronic alcohol use (Le Fauve et al., 2003; NIAAA, 1999). Racial differences in mortality rates due to alcohol related liver disease show Blacks are disproportionately impacted compared to Whites (Russo et al., 2004). In 1997, U.S. national Black male and female mortality rates for alcohol related cirrhosis were $24-47 \%$ higher than the overall male and female rates, whereas mortality rates for White males and females were 5-14\% lower than overall rates (Stinson et al., 2001). Sempos and colleagues (2003) documented disparities between Blacks and Whites in all-cause mortality and alcohol consumption. The protective health effect of moderate drinking previously identified in Whites was not replicated in Blacks, instead showing a linear increase in mortality for Blacks from abstainers to moderate drinkers and heavy drinkers.

*Correspondence concerning this article should be addressed to Karen G. Chartier, Postdoctoral Fellow, University of Connecticut, School of Medicine, Department of Psychiatry, MC-2103, 263 Farmington Avenue, Farmington, Connecticut, 06030. Telephone: (860) 679-4158; Fax: (860) 679-4077; chartierk@ psychiatry.uchc.edu. 
For women, Becker et al. (1996) identified a higher relative risk of developing alcohol related liver disease compared to men in the general population. Greater vulnerabilities for other medical conditions among women with alcohol dependence are also evident. UrbanoMarquez et al. (1995) found cardiomyopathy to be equally common in male and female alcoholics, despite female alcoholics having only $60 \%$ mean lifetime dose of alcohol compared to male alcoholics. Hommer and colleagues (2001) identified alcoholic women as more susceptible to alcohol induced brain damage with fewer years of heavy drinking.

Factors related to the patterns of alcohol consumption among alcohol dependent persons have also been shown to increase their risk for health consequences. Persistent heavy drinking is most notably associated with the development of physical health problems (Corrao et al., 2004; Rehm et al., 2003), while an early onset of alcohol use is linked with both heavy drinking and a greater risk for developing alcohol dependence (Hingson et al., 2006). A parental history of alcoholism (V. M. Hesselbrock et al., 1982; Worobec et al., 1990), and both co-occurring psychiatric disorders (Goldstein et al., 2007; Kirchner et al., 2002) and illicit drug use (De Alba et al., 2004; Pennings et al., 2002) with alcohol use disorders are also linked to heavy alcohol use and the adverse health consequences of use.

Explanations for racial/ethnic differences in physical health primarily focus on social factors. Williams and Jackson (2005) identified disparities in medical care and socioeconomic status as important contributors to differences in health between Blacks and other racial or ethnic groups. King and Williams (1995) in their model of race and health further delineate health practices (e.g., alcohol use), stress, and medical care as intervening variables between socioeconomic factors and health outcomes. Differences between men and women in alcohol use, utilization of medical services, and socioeconomic status may account for gender differences in physical health (Rieker \& Bird, 2005). As well, depression has been associated with women's increased morbidity compared with men (Gorman \& Read, 2006). Friedmann et al. (2003) recognized psychiatric comorbidity as a strong predictor of health outcomes for individuals with alcohol dependence.

The purpose of the present study was to examine the influences of ethnicity and gender on factors associated with physical health in lifetime alcohol dependent adults drawn from the U.S. general population. A study model developed from our review of relationships and factors reported in the literature was tested. The hypothesized model predicted that a family history of alcoholism, socioeconomic status (i.e., income and education) affect health consequences through the mediating variables of alcohol use patterns, co-occurring drug dependence, psychiatric comorbidity, stress, and medical care (See Figure 1). While disparities for Blacks and women in the impact of alcohol consumption on poor health have been identified, ethnic and gender differences in variables predicting physical health in persons with alcohol dependence are not well researched. The moderating effects of ethnicity and gender on factors impacting health were examined in White men, White women, Black men, and Black women with lifetime alcohol dependence who participated in U.S. National Epidemiologic Survey on Alcohol and Related Conditions, NESARC (Grant \& Dawson, 2006).

\section{Methods}

\section{Design}

A secondary analysis of the publicly available NESARC, Wave 1 was conducted (Grant \& Dawson, 2006). The NESARC is a general population survey administered by the National Institute on Alcohol Abuse and Alcoholism (NIAAA). Wave 1 data, collected between 2001 and 2002 in face-to-face interviews, are cross-sectional. The final sample included 43,093 respondents, representing U.S. civilian, non-institutionalized adults, aged 18 and older, from 
all 50 states and the District of Columbia. A multistage stratified probability sampling method was utilized in selecting the sample, and Black and Hispanic households and young adults, age 18 to 24 years, were oversampled (Grant \& Dawson, 2006).

\section{Subjects}

The study sample included all non-Hispanic Black and non-Hispanic White respondents with a lifetime DSM-IV alcohol dependence diagnosis $(n=3,852)$ selected from the full NESARC sample $(N=43,093)$. The diagnosis for lifetime DSM-IV alcohol dependence was generated from the Alcohol Use Disorder and Associated Disabilities Interview ScheduleDSM-IV Version (AUDADIS-IV) administered for the NESARC survey. The reliability of AUDADIS-IV alcohol dependence diagnoses in test-retest studies is reported to be good to excellent for past year $(\kappa=0.76)$ and prior to past year $(\kappa=0.73)$ (Grant et al., 1995). The NESARC survey was reviewed and approved by both the U.S. Census Bureau and the U.S. Office of Management and Budget. All potential NESARC respondents were informed in writing about the nature of the survey, the confidentiality of identifiable survey information, and the voluntary aspect of their participation (Grant \& Dawson, 2006). Only individuals consenting to participate were interviewed.

\section{Measures}

Health consequences were computed for each subject by summing the number of positive diagnoses within the last 12 months as reported to the subject by a doctor or other health professional. The eleven medical conditions queried included: hardening of the arteries, hypertension, cirrhosis, other liver disease, chest pain, rapid heart beat, heart attack, other heart disease, stomach ulcer, gastritis, and arthritis, in addition to injury causing need for medical help or a reduction in usual activities.

Income included 21 categories of annual household income, which ranged from less than $\$ 5,000$ to $\$ 200,000$ or more.

Education included 4 categories, (1) less than high school education, (2) high school education or GED, (3) some college, and (4) bachelor's degree or more.

Family history of alcoholism was determined by each subject's report of blood/natural parental alcoholism or problem drinking. Categories included: both parents, one parent (i.e. either mother or father), and neither parents ever an alcoholic or problem drinker.

Alcohol use patterns were assessed using four separate heavy alcohol use variables: (1) number of years of heaviest drinking, (2) quantity of drinks (i.e. usual number of standard drinks) on drinking days during period of heaviest drinking, and (3) frequency of drinking any alcohol during period of heaviest drinking, ranging from drinking one or two times per year to drinking every day. (4) "Age of regular drinking onset" (i.e., age when respondent began drinking at least once a week) was also utilized. Alcohol exposure is defined by both the patterns of alcohol consumption (e.g., heavy drinking) and volume of consumption in determining the affect of alcohol on health (Rehm et al., 2003). Four features of alcohol consumption were assessed in the current study to reflect the different aspects of alcohol consumption and to evaluate their distinct relationship to physical health. Alcohol frequency and volume consumption measures gathered by the AUDADIS-IV show good to excellent test-retest reliability in the general population, $I C C=0.68-0.84$ (Grant et al., 2003).

Co-occurring drug dependence was defined by a positive lifetime DSM-IV diagnosis for cocaine, heroin, and/or marijuana dependence along with alcohol dependence. The reliability of the DSM-IV drug dependence diagnoses, including past year and prior to past 
year, generated by the AUDADIS-IV are reported to be good to excellent $(\kappa=0.66-0.91)$ (Grant et al., 1995).

Psychiatric comorbidity included the separate DSM-IV lifetime diagnoses of major depressive disorder and antisocial personality disorder (ASPD) along with alcohol dependence. The major depression diagnosis excluded cases where the disorder was entirely attributable to physical illness, alcohol use, and/or drug use. The AUDADIS-IV derived diagnoses of major depressive disorder $(\kappa=0.65)$ and ASPD $(\kappa=0.67)$ show good testretest reliability (Compton et al., 2005; Grant et al., 2003).

Stress was calculated per subject by summing across different stressful life events experienced in the preceding year. The events queried included: death of a family member/ friend; serious illness in a family member/friend; change in living arrangements; problems with neighbor/friend/relative; relationship change; trouble with boss/coworker; job change; fired or laid off; sustained unemployment; major financial crisis; trouble with police; and criminal victimization. Scores ranged from 0 to 12 stressful life events.

Medical care was defined as utilization (yes/no) of inpatient and/or emergency room hospital care in the last 12 months.

\section{Data Analysis}

Study variables, derived from the Wave 1 NESARC data set, were screened for the assumptions of multivariate analysis. When necessary, appropriate data transformations were applied. Descriptive statistics were generated using SUDAAN 9.0.1 (Research Triangle Institute, 2002). Results are based on weighted survey data to reflect the NESARC's multistage stratified probability sampling strategy and to be representative of the U.S. civilian, non-institutionalized adult population.

For this study, the tested model predicts that a family history of alcoholism, income, and education (i.e., exogenous variables) affect health consequences through the mediating variables of alcohol use patterns, co-occurring drug dependence, psychiatric comorbidity, stress, and medical care. The model was tested using structural equation modeling (SEM) with the software package Mplus (version 3.13; Muthen \& Muthen, 2005), which allowed for the use of sampling weights during model testing. The variance-adjusted weighted least squares (WLSMV) method was used to estimate the model, and the Root Mean Square Error of Approximation (RMSEA) and Comparative Fit Index (CFI) served as measures of overall model fit. The model $\chi^{2}$ statistic was not used to assess model fit due to its sensitivity to large sample size (Kline, 2005). RMSEA values $\leq .05$ were employed to indicate close approximate fit and between .05 and .08 reasonable error of approximation (Kline, 2005). CFI values between .90 and .95 indicated adequate model fit and values $>.95$ good fit (Byrne, 2001).

Four groups were examined using a multiple-group path model, including White men ( $n=$ $2,003)$, White women $(n=1,218)$, Black men $(n=387)$, and Black women $(n=244)$. Group differences in model paths were tested by implementing cross-group equality constraints. First, paths from exogenous variables to mediator variables (i.e., gamma coefficients) were constrained to be equal across the four groups. Group differences were tested separately at this step in the following: (a) paths between the exogenous variable family history of alcoholism and mediator variables, (b) paths between income and mediator variables, and (c) paths between education and mediator variables. As a second step, group differences were assessed in paths between mediator variables and the dependent variable of health consequences (i.e., beta coefficients). All paths between mediator variables and health consequences were concurrently constrained to be equal. 
The fit of each constrained model, including equal gamma models ( $2 \mathrm{a}, 2 \mathrm{~b}$, and $2 \mathrm{c}$ ) and the equal beta model (3), was compared with the unconstrained baseline model (1) using CFI and RMSEA fit measures. Constrained paths were assumed to be equal across groups if model fit remained relatively unchanged or improved from the unconstrained to a constrained model. Reduced model fit indicated group inequality in the tested constrained paths. When reduced fit was identified, constrained paths were tested individually. Statistically significant modification indices (M.I.), $\chi^{2}(1)>3.84, p<.05$, were used to locate likely group differences on individual paths. Unstandardized path coefficients in the unconstrained baseline model (1) were also evaluated to describe group differences. Alternatively, unstandardized coefficients in the constrained models were evaluated when cross-group equality constraints did not suggest group differences. Path coefficients were determined to be statistically significant at $z>1.96, p<.05$.

\section{Results \\ Descriptive Statistics}

This U.S. general population sample of persons with alcohol dependence $(n=3,852)$ was $91.32 \%$ White, $66.30 \%$ male, and had a mean age of 38.90 years ( $S E 0.25$ ). Forty percent (40.06\%) of the sample reported parental alcoholism or problem drinking in either one or both parents. Approximately $61 \%$ had an educational level of some college or greater. Sixtyfive percent (64.65\%) were employed full-time (35+ hours per week), with a median annual household income of $\$ 49,875$ ( $S E$ 955.35). These adult men and women had a 0.79 ( $S E$ 0.02 ) mean number of health consequences; $46.89 \%$ of them reported being diagnosed with at least one medical condition in the last 12 months and $18.25 \%$ reported two or more. Injury (24.66\%), high blood pressure (16.25\%), arthritis (14.24\%), gastritis (4.94\%), and chest pain $(4.77 \%)$ were the most frequently reported medical conditions by participants. Blacks compared to Whites reported a higher rate of all adverse health consequences with the exception of injury. Men reported higher rates than women for injury, liver disease, and most conditions involving the heart or blood vessels. The mediator variables modeled to impact health consequences in this alcohol dependent sample are summarized in Table 1.

\section{Model Testing}

Figure 1 provides an illustration of the path model tested for ethnic and gender differences in health consequences for persons with alcohol dependence. All variables in the study model are observed. The model shows the dependent variable, health consequences, affected by the exogenous variables of a family history of alcoholism, income, and education through several mediating variables. The alcohol use variables, age of regular drinking onset, and years, quantity, and frequency of heaviest drinking are mediators in the model, as are lifetime DSM-IV diagnoses of drug dependence, ASPD and/or major depressive disorder, stress, and medical care.

In preliminary analyses, non-significant $(p>.05)$ paths between exogenous and mediator variables were trimmed from the model. This resulted in removal of the exogenous to mediator paths of (1) income to years of heaviest drinking, (2) income to frequency of drinking, (3) education to stress, and (4) education to ASPD. Covariances were added to the model to adjust for the interrelationship between mediator variables based on M.I. $\geq 10$ (Muthen \& Muthen, 2005). Age of regular drinking onset, years, quantity, and frequency of heaviest drinking, diagnoses of drug dependence, ASPD and major depressive disorder, stress, and medical care were correlated in the model. Covariances are not represented in Figure 1 to allow for a less complicated view of the study model. Age, frequently related to the increased prevalence of health conditions, was not evaluated in the model. The drinking variables of age of regular drinking onset and years of heaviest drinking were strongly 
associated with age, and largely accounted for the variance of age in predicting health consequences. Additionally, lifetime alcohol dependence in the full NESARC sample is associated with younger age groups (i.e., ages 18-44; Hasin et al., 2007), which are less likely to experience the physical health problems of older age.

The model tested across ethnicity and gender groups in predicting health consequences among alcohol dependent subjects showed adequate model-data fit. The RMSEA and CFI values were .080 and .919 , respectively, suggesting the possibility for model-data fit improvement based on criterion for good model fit. However, given the study's focus on group comparisons rather than model fitting, the tested model was deemed acceptable and used as the baseline model against which cross-group equality models were compared. CFI and RMSEA values for all constrained models ( $2 \mathrm{a}, 2 \mathrm{~b}, 2 \mathrm{c}$ and 3 ) were compared against the unconstrained baseline model (1). See Table 2 for model comparisons. Unchanged or improved model fit from the unconstrained model to a constrained model showed equality across groups, while reduced model fit indicated group differences.

\section{Ethnicity and Gender Differences}

Equality or no group differences between White men, White women, Black men, and Black women was assumed for paths from the exogenous variable family history of alcoholism to the mediator variables (equal gamma model 2a). Unstandardized coefficients for this model and the other models tested in predicting health consequences are provided in Table 3. On constrained paths for family history, having one or both parents affected with alcoholism predicted $(p$ 's $<.001)$ a participant's positive diagnosis for antisocial personality disorder, lifetime drug dependence, and lifetime major depressive disorder. A participant's family history of alcoholism was also associated $(p$ 's $<.001)$ with increased medical care utilization, stressful life events, and heavy drinking (i.e., years, quantity and frequency), as well as an earlier age of onset for regular drinking $(p<.001)$.

When constraints were placed on the paths between the exogenous variable income and mediator variables, the equal income gamma model $(2 \mathrm{~b})$ similarly provided support for group equality on tested paths. For both Blacks and Whites, increased income $(p<.001)$ predicted a later age of onset of regular drinking. All other significant relationships ( $p$ 's $<$. $001)$ between income and mediator variables were negative. The participants' reduced annual income predicted medical care utilization and lifetime diagnoses for drug dependence, major depressive disorder and ASPD, in addition to increased stressful life events and quantity of drinks consumed on drinking days.

Conversely, differences between groups (i.e., Black men, Black women, White men, and White women) were suggested on paths between the exogenous variable education and mediator variables, the education gamma model (2c). Both the CFI and RMSEA were reduced in the equal education gamma model. M.I. $(p<.05)$ identified likely group differences on five constrained paths, including paths from education to age of regular drinking onset for White men, $\chi^{2}(1, n=2,003)=4.050$ and White women, $\chi^{2}(1, n=$ $1,218)=5.256$; education to years of heaviest drinking for White women, $\chi^{2}(1, n=1,218)$ $=13.579$ and Black men, $\chi^{2}(1, n=387)=17.805$; and education to frequency of drinking during period of heaviest drinking for White women, $\chi^{2}(1, n=1,218)=4.709$.

Unstandardized coefficients in the baseline model (1) describe these group differences in model paths from education to mediator variables (See Table 3). Across groups, the path for White men showed the strongest effect and was the only statistically significant path $(p<$. 001 ) between education and age of regular drinking onset ( $p$ s $>.05)$. The associations between education and both years of heaviest drinking and frequency of drinking also showed differential effects across groups. The relationship of education to years of heaviest 
drinking was stronger for Black men $(p<.001)$ and Black women $(p<.001)$ compared to White men $(p<.001)$ and particularly White women $(p<.05)$. The path from education to frequency of drinking was strongest for Black women, followed by Black men, White men, and White women $(p$ 's $<.01)$.

Lastly, model fit was relatively unchanged when all paths between mediator variables and health consequences were constrained to be equal, supporting group equality on the tested paths (equal beta model). In this sample of alcohol dependent men and women, a significant positive relationship between medical care utilization and health consequences $(p<.001)$ was shown. Similarly, increased health consequences for Black and White men and women were predicted $(p$ 's $<.001)$ by a later age of regular drinking onset and increased years, quantity, and frequency of heavy drinking. The relationships of illicit drug dependence and other psychiatric disorders with health consequences varied across diagnoses. A participant's positive diagnosis of lifetime major depressive disorder $(p<.001)$ was associated with an increased number of adverse health consequences, while a positive diagnosis of lifetime drug dependence was associated with reduced consequences $(p<.001)$. Neither ASPD nor stressful life events were significant predictors of poor health consequences among these alcohol dependent persons.

\section{Discussion}

This study tested a model of race/ethnicity, gender, and intervening variables as predictors of physical health status in a general population sample of alcohol dependent adult men and women. Nearly half of all participants reported experiencing a medical condition in the past year, and Blacks compared to Whites were disproportionately impacted by the adverse health consequences. Findings generated from the multiple-group model analysis identified both group similarities and differences in model paths linking predictors to health consequences. The socioeconomic factor of education was shown to differentially affect the health consequences of chronic and heavy alcohol use for Black and White men and women with alcohol dependence. However, other factors such as income, a family history of alcoholism, alcohol use patterns, co-occurring drug dependence, psychiatric comorbidity, stress, and medical care, frequently related to the course of alcohol dependence, did not differentiate groups in predicting health consequences.

Specifically, we found that ethnicity moderated the relationship between education and alcohol use, with increased education having a stronger role in reducing the impact of alcohol use on health for Blacks compared Whites with alcohol dependence. Ethnicity has also been shown to moderate the relationship between educational attainment and years of healthy life expectancy (Crimmins \& Saito, 2001) and between employment status and negative drinking consequences (Herd, 1994), with the effects of lower socioeconomic status on health being greater for Blacks than Whites. For this study, the moderating role of ethnicity was supported for education, but not for income, in impacting intervening variables associated with physical health.

In each of the four groups examined, parental alcoholism was indirectly related to the physical health problems of alcohol dependent individuals. Research has shown that parental alcoholism predicts more severe consequences of alcohol use and increased alcohol related problems in offspring (V. M. Hesselbrock et al., 1982; Worobec et al., 1990). The utilization of inpatient hospital or emergency room care was also associated with increased adverse medical consequences. This relationship between the use of medical care and health consequences is commonsensical; however it does not appear to reflect previous studies showing reduced access to medical care for Blacks compared to Whites as a source of racial/ ethnic disparities in health (Williams \& Jackson, 2005). 
Our findings that major depression and heavier alcohol use directly predict increased adverse health consequences supports previously identified relationships between depression and heavy alcohol use and poor physical health. Heavy drinking occasions with intoxication are linked to both chronic and acute health consequences of alcohol (Rehm et al., 2003), while depressive symptoms are predictive of chronic physical health conditions for alcoholics and increased risk for mortality among heavy drinkers (Greenfield et al., 2002; Kirchner et al., 2002). Women are reported to have higher rates of major depressive disorder (MDD) than men in the general population (Hasin et al., 2005). Similarly, Black men in comparison to White men demonstrate a greater stability and prevalence of frequent heavy drinking (Caetano \& Kaskutas, 1995). Nevertheless, these gender and racial/ethnic differences in the prevalence of MDD and patterns of heavy drinking did not translate into subgroup differences in health consequences for alcohol dependence.

Other relationships found between the mediator variables tested and health consequences also appear contrary to the literature. The absence of a lifetime drug dependence diagnosis predicted increased health consequences in this study, which contrasts previous reports of more severe health problems with the combined use of alcohol and other drugs (Kosten, 1991; Pennings et al., 2002). A later onset of regular drinking was also shown to predict increased health consequences, while a diagnosis of ASPD was not a significant predictor. These study findings counter other findings suggesting a more severe course of alcohol dependence for individuals who begin drinking before age 14 and for alcoholics with comorbid ASPD (Hingson et. al, 2006; Goldstein et al., 2007).

The absence of an effect for ASPD and drug dependence in impacting health status may reflect a higher prevalence of these disorders in younger respondents (Goldstein et al., 2007; Stinson et al., 2006) who are typically quite healthy. Among individuals with alcohol use disorders the occurrence of ASPD, drug use disorders, and a younger drinking onset are often interconnected (Goldstein et al., 2007; Grant et al., 2004). These discrepant findings may also reflect differences between general population and clinical samples. Other psychiatric diagnoses (e.g., ASPD and other drug use disorders) with alcohol use disorders may be more important in predicting physical health status in treatment samples where incidences of comorbid psychopathology are more prevalent (Helzer \& Pryzbeck, 1988).

This study's findings should be considered in light of several strengths and limitations. The NESARC data set is a large, representative national adult sample drawn from the general U.S. population. Consequently, findings generated from use of this data set should generalize to many aspects of the general population, but may not be applicable to such excluded populations as institutionalized adults, military personnel living on base, and youth under 18 years of age. Findings from this general population sample may not generalize to alcohol dependent persons in clinical populations. Seventy-five percent $(75.37 \%)$ of the study sample reported never seeking help for their drinking. Fein and Landman (2005) identified more severe heavy alcohol use in treated alcoholics compared to alcoholics who have never been in treatment. As well, educational and employment levels for the study sample may be higher than those reported for alcohol dependent treatment samples (M. N. Hesselbrock et al., 2003).

The NESARC data are cross-sectional in nature, thus limiting our ability to more fully test the causal time and order dependent relationships depicted in the study model. Reliance on self-report for the measurement of study variables may also limit causal conclusions. The current study's findings provide evidence only of possible causal relationships. A more complete assessment of causality requires a longitudinal assessment of the variables examined for a clear ordering of the effect of one variable upon the other. 
Our findings may offer implications for social policy and clinical practice with alcohol dependent individuals. In all groups, the indirect effects for parental alcoholism and lower income were mediated by medical care utilization, heavier drinking, and major depressive disorder in predicting increased adverse health consequences. With this in mind, this study points to the reduction of heavy drinking and addressing major depression as important clinical targets for improving the health status of alcohol dependent clients, and reinforces the need for integrated health, mental health and alcohol treatment services for this population. Samet et al. (2001) and Watkins et al. (2005) advocate coordinated care systems as a means to improve the quality of care delivered to persons with multiple disorders (e.g. health conditions, psychiatric disorders, and alcohol or drug use disorders).

In prevention efforts, the offspring of a parent(s) with alcohol problems (40\% of the current sample) and persons of lower income may serve as important target groups for efforts to reduce the risk of health consequences in adults with lifetime alcohol dependence. As well, the association of medical care utilization with increased health consequences identifies emergency room and inpatient hospital settings as important sites for screening clients for risky alcohol use. Improved screening for alcohol problems by clinicians in these settings and others may be useful for the early detection of alcohol use problems and associated medical conditions. This is the focus of the NIAAA's current approach to alcohol screening and brief intervention, Helping Patients Who Drink Too Much, A Clinician's Guide, for primary care and mental health physicians (NIAAA, 2005). Screening and brief motivational interventions have been found most effective for individuals at earlier stages of addiction who have fewer substance-related problems (Carroll \& Rounsaville, 2006).

The moderating effect of ethnicity for education in impacting heavy drinking emphasizes the importance of addressing socioeconomic barriers to good health through both policy and practice initiatives for Black men and women with alcohol dependence. The disproportionate impact of education on drinking and health problems identified in this study likely reflects the larger social circumstance of Blacks in the United States. Many socioeconomic indicators are not equal across racial/ethnic groups. Compared to Whites, Jackson and Williams (2006) identified Blacks as having higher rates of poverty and unemployment and lower levels of family income and educational attainment. Blacks in the current sample were more likely than Whites to have less than a high school education $(21.49 \%$ vs. $9.95 \%)$ and less likely to have a bachelor's degree or more education $(9.87 \%$ vs. 25.96\%). King and Williams (1995) contend that differences in Black and White health status and risk factors for health will remain until discrepancies in social status are addressed. Similarly, The Robert Wood Johnson Foundation's (2009) campaign to "Build a Healthier American" emphasizes the investigation of factors beyond access to and affordability of health care (e.g. education, income, the environment, housing, early childhood experiences) in improving national health.

\section{Acknowledgments}

We would like to thank Maria Wong, Ph.D. for her help with testing the study model. This work was supported by grants T32AA07290 and P50AA03510 from the U.S. National Institute on Alcohol Abuse and Alcoholism.

\section{References}

Becker U, Deis A, Sorensen TI, Gronbaek M, Borch-Johnsen K, Muller CF, et al. Prediction of risk of liver disease by alcohol intake, sex, and age: a prospective population study. Hepatology. 1996; 23(5):1025-1029. [PubMed: 8621128]

Byrne, BM. Structural equation modeling with AMOS: basic concepts, applications, and programming. Mahwah, NJ: Erlbaum; 2001. 
Caetano R, Kaskutas LA. Changes in drinking patterns among whites, blacks and Hispanics, 19841992. J Stud Alcohol. 1995; 56(5):558-565. [PubMed: 7475037]

Carroll, KM.; Rounsaville, BJ. Behavior therapies: the glass would be half full if only we had a glass. In: Miller, WR.; Carroll, KM., editors. Rethinking substance abuse: what the science shows, and what we should do about it. New York: Guilford Press; 2006. p. 223-239.

Compton WM, Conway KP, Stinson FS, Colliver JD, Grant BF. Prevalence, correlates, and comorbidity of DSM-IV antisocial personality syndromes and alcohol and specific drug use disorders in the United States: results from the national epidemiologic survey on alcohol and related conditions. J Clin Psychiatry. 2005; 66(6):677-685. [PubMed: 15960559]

Corrao G, Bagnardi V, Zambon A, La-Vecchia C. A meta-analysis of alcohol consumption and the risk of 15 diseases. Preventive medicine. 2004; 38(5):613-619. [PubMed: 15066364]

Crimmins EM, Saito Y. Trends in healthy life expectancy in the United States, 1970-1990: gender, racial, and educational differences. Soc Sci Med. 2001; 52(11):1629-1641. [PubMed: 11327137]

De Alba I, Samet JH, Saitz R. Burden of medical illness in drug- and alcohol-dependent persons without primary care. Am J Addict. 2004; 13(1):33-45. [PubMed: 14766436]

Fein G, Landman B. Treated and treatment-naive alcoholics come from different populations. Alcohol. 2005; 36(2):19-26. [PubMed: 16440475]

Friedmann PD, Lemon SC, Anderson BJ, Stein MD. Predictors of follow-up health status in the Drug Abuse Treatment Outcome Study (DATOS). Drug Alcohol Depend. 2003; 69(3):243-251. [PubMed: 12633910]

Goldstein RB, Dawson DA, Saha TD, Ruan WJ, Compton WM, Grant BF. Antisocial behavioral syndromes and DSM-IV alcohol use disorders: results from the National Epidemiologic Survey on Alcohol and Related Conditions. Alcohol Clin Exp Res. 2007; 31(5):814-828. [PubMed: 17391341]

Gorman BK, Read JG. Gender disparities in adult health: an examination of three measures of morbidity. J Health Soc Behav. 2006; 47(2):95-110. [PubMed: 16821505]

Grant BF, Dawson DA. Introduction to the National Epidemiologic Survey on Alcohol and Related Conditions. Alcohol Res Health. 2006; 29(2):74-78.

Grant BF, Dawson DA, Stinson FS, Chou PS, Kay W, Pickering R. The Alcohol Use Disorder and Associated Disabilities Interview Schedule-IV (AUDADIS-IV): reliability of alcohol consumption, tobacco use, family history of depression and psychiatric diagnostic modules in a general population sample. Drug Alcohol Depend. 2003; 71(1):7-16. [PubMed: 12821201]

Grant BF, Harford TC, Dawson DA, Chou PS, Pickering RP. The Alcohol Use Disorder and Associated Disabilities Interview schedule (AUDADIS): reliability of alcohol and drug modules in a general population sample. Drug Alcohol Depend. 1995; 39(1):37-44. [PubMed: 7587973]

Grant BF, Stinson FS, Dawson DA, Chou SP, Ruan WJ, Pickering RP. Co-occurrence of 12-month alcohol and drug use disorders and personality disorders in the United States: results from the National Epidemiologic Survey on Alcohol and Related Conditions. Arch Gen Psychiatry. 2004; 61(4):361-368. [PubMed: 15066894]

Greenfield TK, Rehm J, Rogers JD. Effects of depression and social integration on the relationship between alcohol consumption and all-cause mortality. Addiction. 2002; 97(1):29-38. [PubMed: 11895268]

Hasin DS, Goodwin RD, Stinson FS, Grant BF. Epidemiology of major depressive disorder: results from the National Epidemiologic Survey on Alcoholism and Related Conditions. Arch Gen Psychiatry. 2005; 62(10):1097-1106. [PubMed: 16203955]

Hasin DS, Stinson FS, Ogburn E, Grant BF. Prevalence, correlates, disability, and comorbidity of DSM-IV alcohol abuse and dependence in the United States: results from the National Epidemiologic Survey on Alcohol and Related Conditions. Arch Gen Psychiatry. 2007; 64(7): 830-842. [PubMed: 17606817]

Helzer JE, Pryzbeck TR. The co-occurrence of alcoholism with other psychiatric disorders in the general population and its impact on treatment. J Stud Alcohol. 1988; 49(3):219-224. [PubMed: 3374135]

Herd D. Predicting drinking problems among black and white men: results from a national survey. $\mathrm{J}$ Stud Alcohol. 1994; 55(1):61-71. [PubMed: 8189728] 
Hesselbrock MN, Hesselbrock VM, Segal B, Schuckit MA, Bucholz K. Ethnicity and psychiatric comorbidity among alcohol-dependent persons who receive inpatient treatment: African Americans, Alaska natives, Caucasians, and Hispanics. Alcohol Clin Exp Res. 2003; 27(8):13681373. [PubMed: 12966342]

Hesselbrock VM, Stabenau JR, Hesselbrock MN, Meyer RE, Babor TF. The nature of alcoholism in patients with different family histories for alcoholism. Prog Neuropsychopharmacol Biol Psychiatry. 1982; 6(4-6):607-614. [PubMed: 6891822]

Hingson RW, Heeren T, Winter MR. Age at drinking onset and alcohol dependence: age at onset, duration, and severity. Arch Pediatr Adolesc Med. 2006; 160(7):739-746. [PubMed: 16818840]

Hommer D, Momenan R, Kaiser E, Rawlings R. Evidence for a gender-related effect of alcoholism on brain volumes. Am J Psychiatry. 2001; 158(2):198-204. [PubMed: 11156801]

Jackson, PB.; Williams, DR. The intersection of race, gender, and SES: health paradoxes. In: Schulz, AJ.; Mullings, L., editors. Gender, race, class, and health: intersectional approaches. San Francisco: Jossey-Bass; 2006. p. 131-162.

King, G.; Williams, DR. Race and Health: A Multidimensional Approach to African-American Health. In: Amick, BC., III; Levine, S.; Tarlov, AR.; Chapman Walsh, D., editors. Society and Health. New York: Oxford University Press; 1995. p. 93-130.

Kirchner JE, Curran GM, Thrush CR, Owen RR, Fortney JC, Booth BM. Depressive disorders and alcohol dependence in a community population. Community Ment Health J. 2002; 38(5):361-373. [PubMed: 12236407]

Kline, RB. Principles and Practice of Structural Equation Modeling. 2. New York: The Guilford Press; 2005.

Kosten TR. Client issues in drug abuse treatment: addressing multiple drug abuse. NIDA Res Monogr. 1991; 106:136-151. [PubMed: 1922284]

Le Fauve CE, Lowman C, Litten RZ 3rd, Mattson ME. Introduction: National Institute on Alcohol Abuse and Alcoholism workshop on treatment research priorities and health disparities. Alcohol Clin Exp Res. 2003; 27(8):1318-1320. [PubMed: 12966328]

Muthen, LK.; Muthen, BO. Mplus User's Guide. 3. Los Angeles: Muthen and Muthen; 2005.

National Institute on Alcohol Abuse and Alcoholism. 1999Are women more vulnerable to alcohol's effects? [Electronic Version]. Alcohol Alert. Retrieved November 21, 2005 from http:// pubs.niaaa.nih.gov/publications/aa46.htm

National Institute on Alcohol Abuse and Alcoholism. 2000Alcohol and health, 10th special report to the U.S. congress from the secretary of Health and Human Services. Retrieved January 18, 2008. from http://pubs.niaaa.nih.gov/publications/10report/intro.pdf

National Institute on Alcohol Abuse and Alcoholism. 2005Helping patients who drink too much: a clinician's guide. Retrieved May 14, 2007. from http://pubs.niaaa.nih.gov/publications/ Practitioner/CliniciansGuide2005/guide.pdf

Pennings EJ, Leccese AP, Wolff FA. Effects of concurrent use of alcohol and cocaine. Addiction. 2002; 97(7):773-783. [PubMed: 12133112]

Rehm J, Room R, Graham K, Monteiro M, Gmel G, Sempos CT. The relationship of average volume of alcohol consumption and patterns of drinking to burden of disease: an overview. Addiction. 2003; 98(9):1209-1228. [PubMed: 12930209]

Research Triangle Institute. SUDAAN User's Manual (Version 8.0). Research Triangle Park, NC: Research Triangle Institute; 2002.

Rieker PP, Bird CE. Rethinking gender differences in health: why we need to integrate social and biological perspectives. J Gerontol B Psychol Sci Soc Sci. 2005; 60(Spec No 2):40-47. [PubMed: 16251589]

Robert Wood Johnson Foundation. 2009The Commission to Build a Healthier American. Retrieved January 31, 2009, from http://www.commissiononhealth.org/

Room R, Babor T, Rehm J. Alcohol and public health. Lancet. 2005; 365(9458):519-530. [PubMed: 15705462]

Russo D, Purohit V, Foudin L, Salin M. Workshop on Alcohol Use and Health Disparities 2002: a call to arms. Alcohol Fayetteville, NY. 2004; 32(1):37-43. 
Samet JH, Friedmann P, Saitz R. Benefits of linking primary medical care and substance abuse services: patient, provider, and societal perspectives. Arch Intern Med. 2001; 161(1):85-91. [PubMed: 11146702]

Sempos CT, Rehm J, Wu T, Crespo CJ, Trevisan M. Average volume of alcohol consumption and allcause mortality in African Americans: the NHEFS cohort. Alcohol Clin Exp Res. 2003; 27(1):8892. [PubMed: 12544011]

Stinson FS, Grant BF, Dawson DA, Ruan WJ, Huang B, Saha T. Comorbidity between DSM-IV alcohol and specific drug use disorders in the United States: results from the National Epidemiologic Survey on Alcohol and Related Conditions. Alcohol Res Health. 2006; 29(2):94106.

Stinson FS, Grant BF, Dufour MC. The critical dimension of ethnicity in liver cirrhosis mortality statistics. Alcohol Clin Exp Res. 2001; 25(8):1181-1187. [PubMed: 11505049]

Urbano-Marquez A, Estruch R, Fernandez-Sola J, Nicolas JM, Pare JC, Rubin E. The greater risk of alcoholic cardiomyopathy and myopathy in women compared with men. Jama. 1995; 274(2):149154. [PubMed: 7596003]

Watkins KE, Hunter SB, Burnam MA, Pincus HA, Nicholson G. Review of treatment recommendations for persons with a co-occurring affective or anxiety and substance use disorder. Psychiatr Serv. 2005; 56(8):913-926. [PubMed: 16088007]

Williams DR, Jackson PB. Social sources of racial disparities in health. Health affairs Project Hope. 2005; 24(2):325-334. [PubMed: 15757915]

Worobec TG, Turner WM, O'Farrell TJ, Cutter HS, Bayog RD, Tsuang MT. Alcohol use by alcoholics with and without a history of parental alcoholism. Alcohol Clin Exp Res. 1990; 14(6): 887-892. [PubMed: 2088125] 


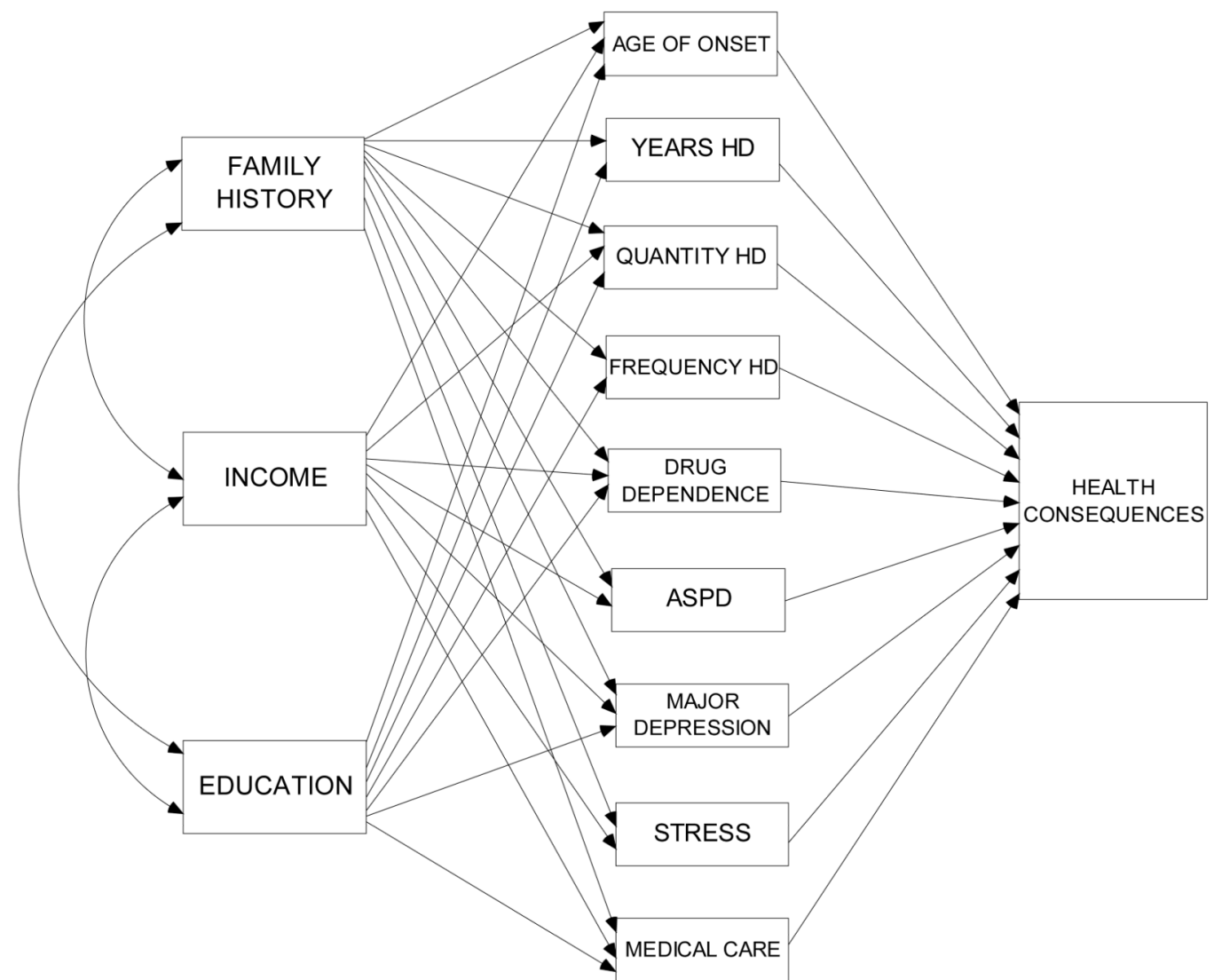

Figure 1.

Model tested for ethnicity and gender differences in adverse health consequences for adults with alcohol dependence.

Note. FAMILY HISTORY = family history of alcoholism; AGE OF ONSET $=$ age of regular drinking onset; YEARS HD = years of heaviest drinking; QUANTITY HD = quantity of heaviest drinking; FREQUENCY HD = frequency of heaviest; ASPD = antisocial personality disorder. 


\section{Table 1}

Mediators Predicting Health Consequences in Adults with Lifetime Alcohol Dependence $(n=3,852)$

\begin{tabular}{lc}
\hline Mediators & $\%$ \\
\hline Frequency of Drinking, Period of Heaviest Drinking & 50.05 \\
Everyday or Nearly Everyday & 36.81 \\
2 to 4 times a week & 7.45 \\
Once a week & 5.69 \\
$\quad$ Less than weekly & 11.20 \\
Co-occurring Drug Dependence & \\
Psychiatric Comorbidity & 32.80 \\
$\quad$ Major Depressive Disorder & 13.47 \\
$\quad$ Antisocial Personality Disorder & 28.47 \\
Medical Care (utilized) & $M(S E)$ \\
\hline & $5.47(0.12)$ \\
\hline Years of Heaviest Drinking & $7.56(0.12)$ \\
No. of Standard Drinks per Drinking Day, Period of Heaviest Drinking & $16.90(0.07)$ \\
Age of Regular Drinking Onset & $2.62(0.04)$ \\
\hline Stressful Life Events &
\end{tabular}


Table 2

Model Comparisons: Cross-group Equality Constraints

\begin{tabular}{lcc}
\hline Model & CFI & RMSEA \\
\hline 1. Baseline model & .918 & .081 \\
2. Equal gamma models & & \\
a. Family history & .923 & .076 \\
b. Income & .925 & .077 \\
c. Education & .880 & .095 \\
3. Equal beta model & .919 & .081 \\
\hline
\end{tabular}

Note. All equal gamma and beta models were compared with the baseline model.

CFI = Comparative Fit Index; RSMEA = Root Mean Square Error of Approximation. 


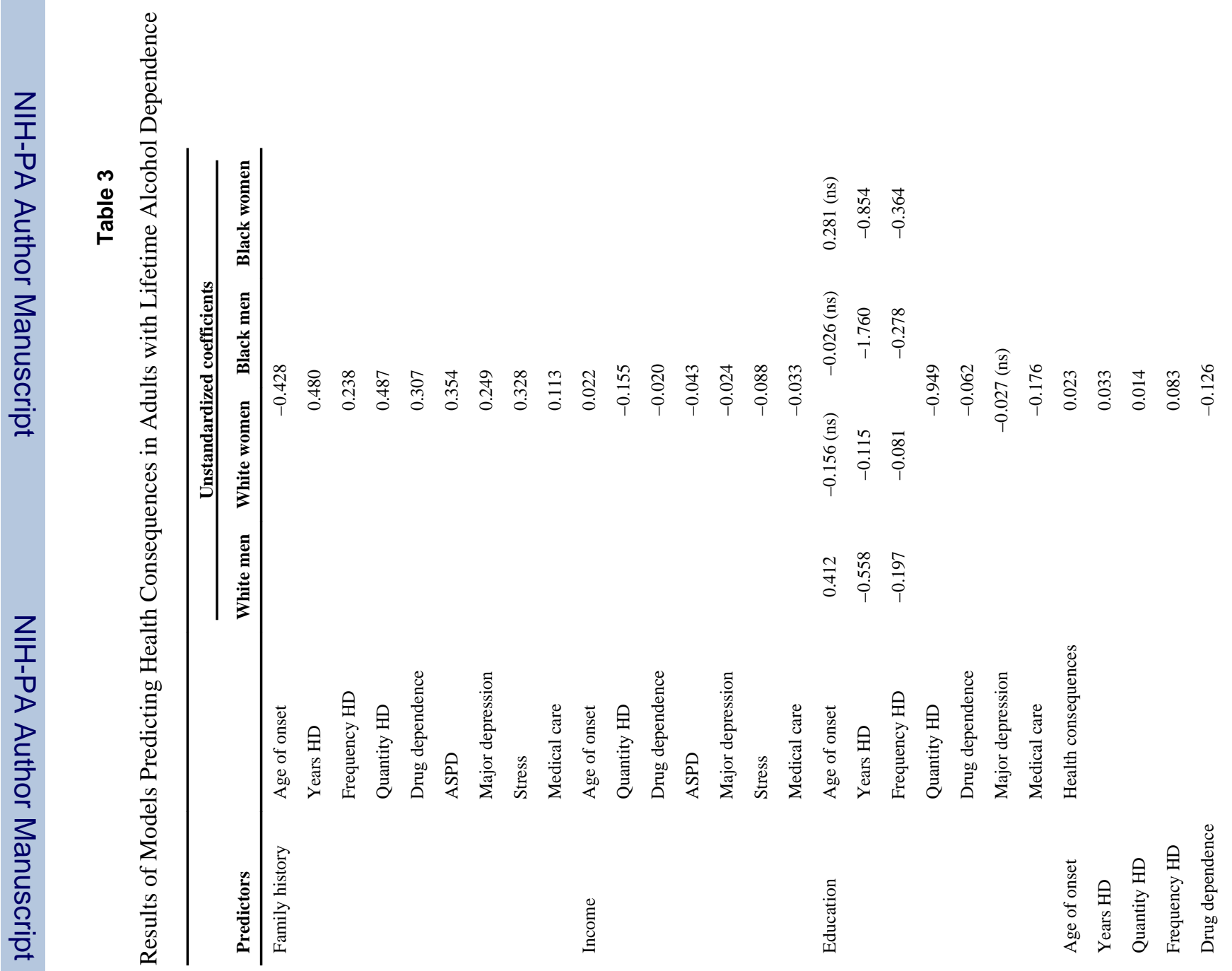




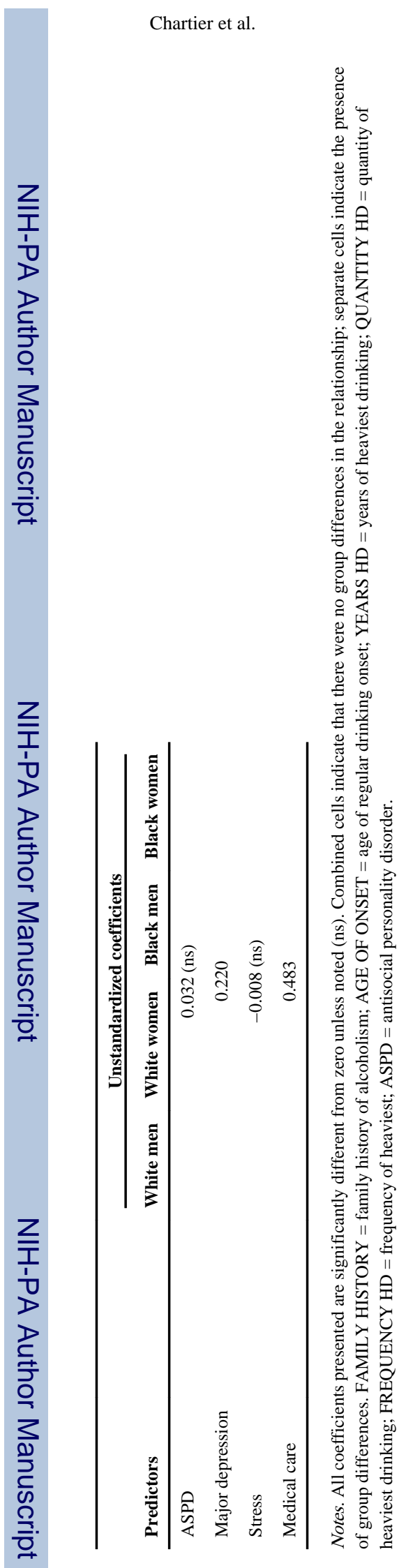

Subst Use Misuse. Author manuscript; available in PMC 2014 February 01. 